\title{
A relação entre instituições, fatores humanos e segurança operacional na aviação
}

\section{The relationship between institutions, human factors and operational safety in aviation}

\author{
Paulo Cezar Rodrigues Villas Bôas ${ }^{1}$ \\ Prof. Dr. of the Faculty of Aeronautical Sciences, Pontifical Catholic University of Rio Grande do Sul - FACA PUCRS, Porto Alegre, RS. Commander of Douglas MD11, \\ Boeing B767 and B737, Lockheed Electra and Embraer Phenom 300. Flown with VARIG, Ethiopian Airlines and GOL, having held the position of Director of Operations \\ and Chief Pilot at Bertol Aerotaxi.
}

\begin{abstract}
RESUMO
Este trabalho pretende enfatizar a relação entre organização e indivíduo, ou seja, o papel da cultura organizacional na implementação dos fatores humanos no cotidiano operacional de uma empresa aérea e a influência deste processo no grau de segurança operacional. Objetiva, de forma concisa, apresentar parte do conjunto de conceitos que formam os fatores humanos em aviação, incluindo, a doutrina CRM. Cultura organizacional, processos psicossociais e tecnologia embarcada são correlacionados de forma processual, evidenciando a perspectiva sistêmica dos fatores humanos em aviação. A conclusão mais relevante recai na importância do comprometimento institucional com fatores humanos, influenciando positivamente o grau de segurança operacional das organizações.
\end{abstract}

PALAVRAS-CHAVE: Arranjo Institucional; CRM; Gerenciamento; Segurança operacional; Aviação

\begin{abstract}
This paper aims to examine the relationship between the organization and the individual, i.e., the role of organizational culture on the implementation of human factors in the daily operations of an airline company, and the influence of this process on the level of operational safety. It intends to concisely present part of the set of concepts that form the human factors in aviation, including CRM procedures. Organizational culture, psychosocial processes and airborne technology are correlated in a procedural form, demonstrating the systemic perspective of human factors in aviation. The most relevant conclusion lies in the importance of institutional commitment to human factors, positively influencing the level of operational safety of organizations.
\end{abstract}

KEYWORDS: Institutional Design, CRM, management, safety, aviation.

Pontifical Catholic University of Rio Grande do Sul Porto Alegre, RS, Brazil

Editor

Thaís Russomano

Microgravity Centre PUCRS, Brazil

Executive Editor

Rafael Reimann Baptista

Faculdade de Educação Física e Ciências do Desporto, PUCRS, Brazil

e-ISSN: 2179-703X
Corresponding Author:

Paulo Cezar Rodrigues Villas Boas

pvillas@gmail.com

Received: December 15, 2014 Accepted: December 26, 2014

(C) 2014 EDIPUCRS 


\section{Introdução}

No intuito de elucidar e contextualizar alguns dos conceitos presentes em fatores humanos em aviação, se faz necessário discutir o papel das instituições e a sua correlação com a segurança operacional (segurança de voo).

Com o incremento tecnológico das aeronaves o fator humano ganhou relevância quando comparado com a confiabilidade dos equipamentos. Em outras palavras, os aviões passaram a apresentar menos avarias fatais e a falha humana letal ganhou destaque em função da crescente complexidade operativa, produto da tecnologia embarcada. Este contexto propiciou a emergência de estudos focados em fatores humanos, dos quais cursos como o CRM (gerenciamento de recursos em equipe) ganhou destaque, objetivando a mitigação de erros em prol da segurança das operações de voo.

No entanto, supõe-se que a qualificação e o treinamento das equipes em fatores humanos não é completamente eficiente se não houver o comprometimento institucional com o tema, ou seja, que o setor diretivo de uma empresa de transporte aéreo esteja realmente comprometida com uma cultura de segurança operacional pró-ativa.

\section{Arranjo institucional}

Cultura organizacional ou o arranjo institucional é a maneira como se molda institucionalmente uma organização, podendo influenciar diretamente no comportamento dos indivíduos. Empresas de aviação possuem arranjos institucionais que podem estar ou não focados na relevância dos fatores humanos e da segurança operacional na aviação.

A cultura de uma empresa ou organização representa um vetor de vital importância no equacionamento dos comportamentos e respostas dos indivíduos. Uma organização que basicamente apenas sanciona as ações individuais apresenta resultados diferenciados daquela que os aplica coletivamente (Anca et al., 2010:13). Regras institucionais diferentes produzem variações nas preferências dos indivíduos (North, 1990:81). As instituições regulam as escolhas dos indivíduos (Goodin, 1996:09). Tripulantes, despachantes e mecânicos, entre outros, que participem de uma organização cujo arranjo institucional promova, incentive e fiscalize efetivas práticas de segurança operacional, podem aceitar e assimilar cursos como o CRM mais facilmente.

$\mathrm{O}$ arranjo institucional representa as regras do jogo em uma empresa, são os balizamentos socialmente criados que dão forma as relações humanas. Elas reduzem as incertezas promovendo a estrutura do cotidiano. Estas incertezas emergem num contexto de informações incompletas sobre o comportamento dos outros indivíduos no processo de interação humana. As instituições apresentam aspectos formais e informais. Os primeiros são caracterizados pelos regulamentos e procedimentos formais, os outros são determinados pelas convenções, normas e padrões de conduta. Os enquadramentos informais são inescritos, correspondendo a formas de comportamento que subjazem e complementam as regras formais. São informações socialmente transmitidas (North, 1990:03-04).

Organizações são grupos de indivíduos unidos por propósitos comuns, em busca destes objetivos (North, 1990:05). As instituições podem fornecer informações, reduzir os custos de transação, dar maior credibilidade aos acordos, estabelecer princípios de coordenação, facilitar as operações recíprocas e mudar a concepção dos agentes em relação aos seus interesses. A coordenação de crenças, obtida por meio das instituições, evita as instabilidades das ações coletivas (Goodin e Klingemann, 1998:469-70).

A principal característica das instituições é a de reduzir o cenário de imprevisibilidade promovendo uma estrutura de interação humana estável, definindo a motivação e a função de utilidade dos indivíduos, bem como os custos de transação e transformação. As instituições balizam as trocas e mudanças promovidas pelas pessoas (North, 1990:06) Também garantem o cumprimento dos contratos, por meio de um cenário de continuidade no quais os benefícios advindos superam os custos da violação. Ao reduzirem a desinformação, as instituições induzem a cooperação dos indivíduos. Promovem um quadro de regulação, restrição e observância, que juntos propiciam transações a um custo compatível para as partes. Desta forma promovem um escopo de oportunidades e incentivos para todos (North, 1995:25). Com regras claras, precisas e impessoais é possível aumentar a produtividade e cooperação entre os funcionários de uma empresa aérea, bem como fortalecer uma visão coletiva na qual a segurança operacional possa ser um valor institucional inestimável.

As instituições também promovem a tentativa de solução de problemas considerados fundamentais como as escolhas e ações coletivas. Os indivíduos, numa empresa, possuem comportamento estratégico, visando agregar o máximo de vantagens individuais, num cenário institucionalmente balizado. Portanto, as instituições promovem o incremento da previsibilidade, reduzindo incertezas e favorecendo a estabilidade nas relações humanas. A manutenção de um arranjo institucional é menor que o dispêndio existente no contexto da incerteza (Goodin e Klingemann, 1988:647-8). Se 
erros não intencionais são tratados coercitivamente, a consequência imediata pode passar pela omissão e falta de cooperação das equipes, evidenciando um contexto de deterioração nas práticas operacionalmente seguras.

O dilema ou impasse da ação coletiva é caracterizado pelo comportamento racionalmente orientado dos indivíduos que pode levar a um resultado incerto ou imprevisível, favorecendo a formação de um cenário de desequilíbrio. No caso, cada agente adota uma estratégia própria, desconsiderando a possibilidade de coordenação com o outro. Na condição de equilíbrio, cada indivíduo adota uma estratégia visando à coordenação com os outros, mesmo que haja um custo na alteração da estratégia. Isto ocorre devido aos custos de transferência serem menores que os da desordem (Cox e McCubbins, 1993:86-8). Arranjos institucionais ou culturas organizacionais confusas, de caráter pessoal, favorecendo determinadas pessoas, em detrimento da impessoalidade, podem desagregar a produtividade das equipes. Por exemplo, a lista de senioridade para tripulantes é uma ferramenta que pode ser utilizada como uma garantia de imparcialidade na evolução profissional. No entanto, a mesma não necessariamente abrange todos os setores de uma determinada empresa aérea, cuja seleção pode ocorrer em função de regras informais.

As instituições regulam a intermediação de interesses, definindo as regras do jogo e os ganhos angariados neste (Goodin e Klingemann, 1998:685). O jogo é uma representação formal das escolhas estratégicas. Ele consiste num conjunto de jogadores, na especificação das opções ou estratégias dos jogadores, na descrição dos resultados possíveis diante das opções escolhidas pelos jogadores e na determinação dos ganhos de cada jogador em relação aos resultados obtidos. $\mathrm{Na}$ padronização ou coordenação dos jogos, o problema é a incerteza em relação às estratégias que serão adotadas. Se a opção dos indivíduos for pelo equilíbrio, ainda existe a dificuldade em coordenar a estratégia específica para este fim. Outro dilema da ação coletiva é baseado no fato do indivíduo não confiar e não poder antecipar a jogada do outro, aumentando os custos da ação estratégica e as possibilidades de um cenário de desequilíbrio (Cox e McCubbins, 1993:87-9). Arranjos institucionais que favorecem as ações coletivas coordenadas, que diluam a competição individual, podem implementar o grau de segurança operacional de uma organização. Como hipótese, podemos mencionar a questão da nomeação para as posições de instrutor e checador de voo e simulador, embasada em critérios de proficiência técnica e fatores humanos, podem conferir uma condição de imparcialidade e legitimidade ao arranjo institucional de uma empresa aérea, contribuindo positivamente para as políticas de segurança nas operações de voo.

Os agentes assalariados inseridos no campo das relações de trabalho podem ser considerados racionais, utilitaristas e centrados no interesse, dentro do contexto pelo qual se associa emprego e salário com a própria sobrevivência. Não se pretende reduzir as escolhas dos indivíduos a preceitos unicamente racionais, no entanto, esta estratégia pode ser considerada como preponderante quando esta diretamente relacionada com a manutenção do emprego. Pode se definir "(...) utilidade como uma medida de benefícios, na mente de um cidadão, que ele usa para decidir entre caminhos alternativos de ação" (Downs, 1999:57). Desta forma, o utilitarismo dos empregados estaria centrado na manutenção de benefícios continuados, no caso, a preservação do emprego, do salário e a possibilidade de eventuais promoções. "Por ação racional, entendemos a ação que é eficientemente planejada para alcançar os fins econômicos ou políticos conscientemente selecionados pelo ator" (Downs, 1999:41). Para o autor o "(...) modelo poderia ser descrito como um estudo de racionalidade política de um ponto de vista econômico" (p. 36). Olson (1999:21) afirma que a "(...) combinação de interesses individuais e comuns em uma organização sugere uma analogia com o mercado competitivo".

Olson (1999) formula uma teoria para grupos sociais e organizações baseada na ação individual. De acordo com o autor, as organizações são essencialmente provedoras de benefícios indivisíveis e generalizados para os participantes. Estas não se sustentam sem o oferecimento de vantagens seletivas daquelas disponíveis na esfera pública devido à necessidade de estímulo para seu financiamento, pois os membros de um grupo iriam desejar usufruir os benefícios, rejeitando arcar com o custo de manutenção. O custeio só ocorreria mediante a possibilidade de ganhos diferenciados daqueles que não contribuíssem. Promovendo-se a seletividade nos ganhos, por meio de arranjos institucionais específicos, é possível incrementar o estímulo à participação. A aquisição de benefícios diferenciados por parte dos indivíduos engajados em processo aquisitivo é que irá estimular uma ação racional individual voltada para os objetivos coletivos. Em outras palavras, só ganha quem faz. Através da seletividade de benefícios, o autor procura privilegiar o mérito da ação individual coletivamente orientada em detrimento do oportunismo decorrente do não engajamento.

Olson (1999) e Downs (1999) estão preocupados com a lógica do oportunismo; se um benefício é oferecido para todo um grupo, independente da ação individual em busca referida benesse, a racionalidade 
individual direcionará o agente para o consumo sem contribuição.

Estes fatos podem ser utilizados como suporte na afirmação de que as ações coletivas, no ambiente empregatício de uma empresa aérea, são de ordem racional e estão centradas na utilidade para obtenção e manutenção de um benefício, no caso, o emprego, evidenciando a importância de um arranjo institucional que privilegie o trabalho em equipe e a necessidade de adesão aos procedimentos formais. Os balizamentos estruturais influenciam no comportamento dos indivíduos, bem como evidenciam a necessidade dos indivíduos em racionalizar e maximizar a utilidade de suas ações dentro de fronteiras determinadas por estruturas exógenas (Goodin e Klingemann, 1998: 159-91).

As instituições também podem ser apreendidas, sob a perspectiva histórica. Neste caso as escolhas iniciais e os compromissos resultantes são determinantes nas decisões subsequentes. Se as opções iniciais não são compreendidas, a lógica subsequente do processo também poderá não ser (Peters, 1999). As escolhas efetuadas quando uma instituição está sendo formada, ou quando um procedimento é iniciado, terão expressiva e contínua influência sobre o processo no futuro (Skocpol, 1992). Por meio das escolhas e experiências passadas é que as instituições modulam as preferências do presente, pois a história é o estudo de como o passado influencia o presente e o futuro (Goodin, 1996) ${ }^{1}$.

Neste contexto de continuidade, as instituições correspondem ao principal fator na estruturação das ações coletivas e nas consequências geradas. Os arranjos institucionais priorizam preferências e utilizam fatores acessórios como as ideias, num contexto de interação entre as partes. As instituições, sob o ponto de vista histórico, são procedimentos de ordem formal e informal, rotinas, normas e convenções enraizadas nas organizações, com características que vão sendo moldadas e replicados ao longo do tempo. As instituições, analisadas sob a perspectiva histórica, também consideram o potencial das ideias e crenças na sua composição; que há ênfase na dependência do arranjo inicial; que a relação com o indivíduo é abrangente e que existem assimetrias de poder no seu funcionamento e desenvolvimento. A escolha racional pode ser usada para especificar a relação entre instituições e ação, e pode ser definida como aqueles aspectos do comportamento humano que são instrumentais e baseados no cálculo estratégico.

\footnotetext{
${ }^{1}$ Para maiores esclarecimentos ver Peters (1999), Skocpol (1992) e Goodin (1996).
}

Também assume que os indivíduos procuram maximizar a conquista de objetivos existentes num conjunto de preferências, agindo estrategicamente. Neste contexto, as instituições fornecem as informações relevantes destinadas a orientar o comportamento dos indivíduos, criam mecanismos de cumprimento dos acordos, penalizando aqueles que se afastam do arranjo. Os indivíduos aderem aos padrões de comportamento, pois o custo do abandono é maior que o da incorporação. Quanto mais uma instituição contribuir na resolução dos dilemas da ação coletiva mais eficiente ela será. Desta forma, pode se estabelecer uma ligação entre a análise das instituições sob a perspectiva histórica e a teoria da escolha racional. A idéia da importância das instituições na resolução dos problemas da ação coletiva, que significa fazer a cooperação parecer possível e racional para os agentes envolvidos (ver Hall e Taylor, 1996).

Goodin and Klingemann (1998:684-5) definem as instituições como reguladoras de acesso e da utilização de recursos. Elas delimitam quais interesses e como estes podem ser obtidos. Segundo Boudon, citado por Tsebelis (1998:37): “(...) se a probabilidade de recompensa é pequena, a utilidade esperada de um grande esforço é negativa, e as pessoas param de fazê-lo". Arato e Cohen (1999:10) afirmam que a lógica das ações coletivas também está estruturada em políticas inclusivas. O sucesso das instituições estaria vinculado a sua capacidade de agregar os indivíduos em torno de propósitos comuns, ou seja, transformar membros em participantes . Assim, aderir ao arranjo institucional de uma empresa de aviação pode representar uma estratégia individual inclusiva, ou seja, mantém-se o emprego e as benesses advindas, cumprindo-se os procedimentos institucionalizados pelo arranjo.

A partir da perspectiva institucional acima debatida e possível afirmar que o arranjo institucional existente nas empresas aéreas influência diretamente na eficácia das políticas de segurança operacional adotadas, bem como na efetiva utilização dos fatores humanos. Se os indivíduos não são institucionalmente estimulados a adotar estas práticas e princípios os resultados podem ser questionáveis.

Vale notar as expressivas mudanças na condição do piloto a partir da invenção do avião. De aventureiro audaz ao gerenciamento de sistemas e tomada de decisões, com crescentes responsabilidades e autoridade decrescente fora da cabine de comando, induzindo uma perspectiva de frustração profissional (Blain, 1970:65). Este processo tem consonância com as atitudes dos pilotos em prol de sua valorização profissional, com a consequente tentativa de impor aos outros profissionais 
de uma empresa aérea um padrão comportamental de subserviência, imprimindo lembranças negativas e duradouras naqueles que progrediram a altas posições diretivas (Blain, 1970:64), agregando um cenário complicador na efetiva tentativa de se implementar institucionalmente os fatores humanos em aviação.

Assim, a cultura de segurança de uma empresa aérea é criada a partir dos seus dirigentes sendo permeada por toda a organização e medida na área operacional (Anca et al., 2010:73). Se este cenário não estiver adequadamente estruturado, programas e qualificações como CRM e LOFT podem apenas cumprir os requisitos da agência local de aviação civil ao invés de efetivamente promover mudanças em prol da segurança operacional. Se ressalta, portanto, o papel dos dirigentes de uma empresa aérea na condução deste processo.

\section{Fatores humanos}

Fatores humanos em aviação é o conjunto multidisciplinar que utiliza os princípios e métodos da psicologia social e comportamental, das ciências sociais, da engenharia e fisiologia, a fim de aperfeiçoar o desempenho humano, reduzindo os seus erros na interação com máquinas (Anca et al., 2010:04). Esta perspectiva se baseia na premissa de indivíduos trabalhando em equipes, de forma sinérgica, operando dispositivos, visando o cenário de maior segurança possível. Este conceito agrega os princípios da ergonomia com o trabalho em equipe em prol da segurança das operações de voo. No entanto, se reconhece a falibilidade humana, de forma que se procura continuamente mitigar e gerenciar os erros e ameaças.

Para que estes princípios e métodos sejam compreendidos foram criados programas e conceitos, que nem sempre são devidamente explicitados. Com o objetivo de facilitar este entendimento, lista-se a seguir a reprodução dos mais difundidos.

O CRM (Corporate Resource Management) é a aplicação prática dos princípios dos fatores humanos na área de aviação (Anca et al., 2010:05). Em português a sigla significa gerenciamento dos recursos em equipe. O significado da letra "C" foi mudando em função da abrangência do grupo social considerado. Inicialmente, focada nos pilotos atuando na cabine de comando, seus princípios foram disseminados posteriormente para a tripulação, com a inclusão dos comissários de bordo e todos os setores de uma empresa aérea. Portanto, de Cockpit houve a transição para Crew and Corporate. CRM significa a utilização conjunta de todos os recursos disponíveis (informação, pessoal e equipamentos) de forma que as operações de voo sejam seguras e eficientes. Os conceitos de CRM apregoam o aprimoramento na interface entre indivíduos e máquinas, na aquisição de informações no tempo adequado, em liderança, no trabalho em equipe, na resolução de problemas, na tomada de decisões e constante consciência situacional. Planejamento, vigilância e divisão na carga de trabalho estão diretamente correlacionados com consciência situacional, que se entende, preliminarmente, como a percepção de condições operacionais e contingências, conectadas de forma causal a incidentes ou acidentes.

Cabe ressaltar que acidente e incidente, segundo o documento NSCA 3-13 (CENIPA 2014:08-10) do Comando da Aeronáutica, apresentam definições de amplo espectro. Genericamente, acidente é toda ocorrência aeronáutica relacionada a operação de uma aeronave que resulte em lesão grave ou óbito, bem como, dano material, falha estrutural ou desaparecimento do equipamento. $\mathrm{O}$ incidente, por sua vez, nos termos do mesmo documento, se caracteriza por qualquer evento que afete ou possa afetar a segurança da operação, sem que, no entanto, se configure um acidente. Pode-se depreender que a diferença entre os dois conceitos está fundada no grau das consequências decorrentes de um acontecimento envolvendo indivíduos e aparelhos no cenário de uma operação de voo.

Já NOTECHS (Pilots' Non-Technical Skills) se concentra nas habilidades psicossociais ou habilidades não técnicas, e é uma abordagem paralela aos conceitos de CRM, exclusiva para pilotos. Pode ser definida como o conjunto de aptidões cognitivas e sociais destes tripulantes que não estão diretamente relacionadas com o controle da aeronave, no gerenciamento de sistemas e no cumprimento dos procedimentos operacionais (Anca et al., 2010:185). Portanto, NOTECHS inclui a perspectiva de alerta situacional, processo de tomada de decisões, liderança, trabalho em equipe e a capacidade de lidar com o estresse e a fadiga (Anca et al., 2010:182). Estas aptidões complementam a capacitação técnica dos pilotos, mitigando a emergência de erros ou problemas operacionais. A partir desta definição, se desenvolveu uma metodologia para ser utilizada no NOTECHES. O objetivo foi avaliar individualmente as habilidades psicossociais dos pilotos, analisando deficiências subjacentes, ou seja, as não evidentes, durante as avaliações (recheck).

Tripulações vigilantes despendem a atenção necessária em relação às tarefas requeridas e reagem imediatamente as novas informações. Elevados níveis de comunicação são associados a escassos erros operacionais. Questionamento, assertividade e posicionamento são comportamentos que garantem 
que as informações estejam disponíveis e que a comunicação seja efetivada no tempo apropriado (Anca et al., 2010:137-8).

O LOFT (Line Oriented Flight Training) se refere à utilização de simuladores em conjunto com um cenário de treinamento que reproduza, da forma mais realística possível, o ambiente operacional de um voo, visando o aprimoramento na qualificação de pilotos. Portanto, o treinamento LOFT procura combinar a capacidade dos simuladores em reproduzir fielmente as características de aeronaves com um cenário autêntico, reproduzindo eventos do cotidiano operacional em tempo real. Não se induz os pilotos a erros neste tipo de programa, o treinamento é uma experiência de aprendizado.

O LOSA (Line Oriented and Flight Audit) consiste em um programa que foi idealizado para identificar ameaças latentes a segurança operacional e erros de desempenho da tripulação. O objetivo do LOSA é auditar os processos de gerenciamento das ameaças e erros por parte das equipes. A coleta de dados ocorre por meio do acompanhamento aleatório das operações de voo na cabine de comando. Os observadores do LOSA são qualificados para observar e registrar como as ameaças e erros são encarados e mitigados. As tripulações não são identificadas, e se procura apurar desvios de procedimentos, como aproximações desestabilizadas ou a não leitura de checklists. A análise destas informações, no caso, como as equipes gerenciam as ameaças e os erros, permite que as empresas introduzam contramedidas em prol da segurança operacional.

Portanto, habilidades desenvolvidas por meio dos princípios CRM, como incremento na comunicação, gerenciamento da carga de trabalho e construção de uma doutrina baseada no trabalho em equipe, formam a base de um programa de gerenciamento de ameaças e erros (Anca et al., 2010:287-9).

A comunicação efetiva e a consolidação de um processo de tomada de decisões representam as bases da liderança e do trabalho em equipe. O elemento central neste cenário recai sobre o princípio do quê, e não de quem está certo ou errado. Por meio do gerenciamento das ameaças, a tripulação pode reduzir o grau de erros potenciais durante um voo.

O TEM (Threat and Error Management) é um programa que enfatiza as ameaças e erros passíveis de ocorrerem em um voo, evidenciando as estratégias e contramedidas apropriadas no enfrentamento da questão. Estas estratégias têm um caráter proativo em consonância com a complexidade do ambiente de uma operação aérea. Dados obtidos pelo LOSA propiciaram a estruturação do programa TEM (Anca et al., 2010:297).
O SOPs (Standart Operating Procedures) abarca um conjunto de procedimentos que, quando adequadamente seguido, assegura a emergência de estratégias e contramedidas em prol da segurança operacional. Portanto, proficiência operacional está diretamente relacionada com o comprometimento das tripulações em cumprir na íntegra os procedimentos previstos no SOPs. Aderência ao prescrito é a ideia central que permeia o uso do SOPs. Estatísticas do fabricante Boeing indicam que desvios dos procedimentos previstos no SOPs são fatores contribuintes de aproximadamente um terço de todos os acidentes com fatalidades em aviação. Estes desvios são produto da omissão, ou seja, não fazer algo previsto, ou desacerto, no caso, efetuar um procedimento de forma equivocada ou executar uma ação que não deveria ocorrer (Anca et al., 2010:70-1). A recorrência nos desvios, criando uma normalidade alternativa, na qual os membros das equipes tem consciência de não estarem seguindo os procedimentos é chamada de violação. Violações tendem a ser tratadas no escopo disciplinar, não se atendo unicamente ao viés educativo.

As Normas compõem um conjunto de regras informais, geralmente procedimentos inescritos, que os grupos adotam para regular o comportamento dos seus membros (Anca et al., 2010:89). Normas consonantes com o arranjo institucional ou cultura organizacional de uma organização promovem a estabilidade nas relações entre os membros de um grupo. A estabilidade institucional impacta positivamente o grau de segurança operacional de uma organização.

O Papel social se refere ao conjunto de comportamentos associados a uma posição, cargo ou função em uma organização, grupo ou equipe (Anca et al., 2010:88). Estes comportamentos influenciam diretamente nas relações interpessoais das equipes (Green et al., 1996:105) e são produto das escolhas dos indivíduos. As instituições (Goodin, 1996:09) regulam estas escolhas. Informações incongruentes, ou seja, procedimentos escritos e normas informais divergentes podem causar uma situação de conflito entre os diferentes membros de uma equipe. Da mesma forma, informações imprecisas ou não claramente difundidas podem promover uma situação de ambiguidade no entendimento dos papéis dos indivíduos (Anca et al., 2010:88-9).

O Status é a posição relativa de um indivíduo no conjunto do grupo o qual pertença, ou seja, sua posição hierárquica (Green et al., 1996:104). Geralmente, quanto maior o status do individuo, maior será o seu poder e influência no grupo. $\mathrm{O}$ status, tal qual o papel social, estabelece o adequado comportamento dos membros de um grupo (Anca et al., 2010:90). A 
dificuldade ou desinteresse de uma organização em definir claramente o status de seus membros pode gerar situações de conflito, impactando negativamente o grau de segurança operacional.

O Poder é a possibilidade de impor a própria vontade numa relação social, mesmo ocorrendo resistências (Weber, 1994:33). Esta capacidade tende a ser estruturada na coerção, ou seja, na imposição. $\mathrm{O}$ poder no sentido weberiano influi negativamente os fatores humanos aplicados a aviação.

O Poder Simbólico significa um contexto na qual existe anuência pronta e automática dos membros de uma equipe em relação a autoridade constituída (Bourdieu, 1998:07,08-114). Neste caso, a autoridade pode ser legitimada pelo arranjo institucional existente, ou seja, a organização explicitamente endossa o seu preposto. Isto não significa obediência incondicional, pois líderes e seguidores atuam de acordo com os balizamentos impostos pela organização. Uma dinâmica de autoridade confusa pode ser diretamente associada à emergência de acidentes e incidentes. Autoridade não legitimada pode se transformar em autoritarismo ou apatia. No primeiro, ocorre a emergência da imposição e coerção, no segundo, da omissão.

A Autoridade legitima o uso do poder e da influência, sendo uma construção simbólica de ordem institucional que institui a anuência. Portando, a autoridade se estrutura no princípio da dominação legal que é a possibilidade de se encontrar obediência num cenário de legitimidade e aceitação das ordens instituídas (Weber, 1994:139-41).

A Liderança pode ser conceituada como um processo de interação social entre líderes e seguidores. É um fenômeno de grupo. Aparentemente, o comportamento dos líderes impacta decisivamente no desempenho das equipes (Anca et al., 2010:94-5). Este processo possui elementos estruturais como a capacidade, ou até mesmo, a vontade da organização em legitimar os seus líderes, bem como aspectos individuais, como a capacidade de persuasão dos indivíduos investidos no papel de dirigentes. A liderança somente pode ser exercida sob o princípio da autoridade.

O Cargo significa a posição que uma pessoa ocupa dentro de uma estrutura organizacional. A Função é o conjunto de tarefas e responsabilidades que correspondem a este cargo. $\mathrm{O}$ cargo de piloto é subdividido nas funções de comandante e co-piloto que podem se alternar nas funções de piloto que voa e piloto que monitora. Portanto, PM (Pilot Monitoring) é o piloto que desempenha tarefas de monitoramento e suporte numa cabine de comando, complementando a atuação do outro piloto. E PF (Pilot Flying) é aquele que opera os comandos de voo de uma aeronave.
A principal incumbência do PM é a de efetuar o acompanhamento do voo, bem como o desempenho do PF, objetivando detectar qualquer ameaça ou erro que possa prejudicar o grau de segurança operacional. Se alguma ameaça é detectada, se inicia um processo de ações assertivas que irá identificá-la, anulando assim o erro, ou identificando o erro e anulando as consequências negativas. Monitoramento em voo é uma habilidade que tem que ser treinada, praticada e avaliada. Comandante e co-piloto podem se alternar nas funções de PF e PM.

A Ameaça é um evento que ocorre alheio a influência da tripulação, incrementando a complexidade de uma operação de voo, requerendo atenção e gerenciamento. Por sua vez, o Erro é uma situação inevitável na aviação. As pessoas são falíveis e erram. Partindo desta premissa, o desempenho de uma equipe não pode ser avaliado sob a perspectiva de uma operação efetuada com erros ou sem estes. A ênfase deve ser focada na capacidade de uma equipe em reconhecer ameaças e erros, bem como no gerenciamento destes, de forma que incidentes e acidentes sejam evitados (Anca et al., 2010:68-9).

A Consciência Situacional é a capacidade de integrar operacionalmente a tripulação com a aeronave, de forma que os pilotos estejam constantemente conscientes dos eventos, ações e consequências relacionados ao processo em si (Anca et al., 2010:129). Efetivamente, as tripulações estarão vigilantes, monitorando o ambiente e coletando informações adicionais, procurando e esclarecendo a natureza das ameaças. A avaliação de uma situação passa pela identificação e definição do problema e nível de risco associado, determinando o tempo necessário para a resolução da demanda. A correta avaliação do tempo disponível representa o fator mais relevante no equacionamento das estratégias subsequentes. Tempo disponível pode ser ampliado em procedimentos de espera, redução da carga de trabalho e reordenamento de tarefas. Redução na carga de trabalho pode ser obtida pela coordenação do trabalho em equipe, enfaticamente sinérgico. $\mathrm{O}$ risco pode ser avaliado e gerenciado por meio da correta percepção de ameaças. A probabilidade na emergência de um evento e as possíveis consequências deste representam duas dimensões do risco. Qualificação, treinamento e aderência aos procedimentos preconizados, bem como experiência operacional influem positivamente no grau de consciência situacional dos tripulantes, mitigando a emergência de riscos.

A Tomada de Decisões é a necessidade de elencar alternativas. Estas podem ser adequadas, menos eficientes ou erradas, lembrando que o erro faz parte da condição humana (Anca et al., 2010:20). Desta forma, agências reguladoras, fabricantes de aeronaves, 
empresas aéreas e órgãos de investigação e prevenção de acidentes tentam simplificar as decisões a serem tomadas pelas equipes, estabelecendo ou recomendando alarmes, alertas, ações automatizadas, bem como procedimentos padronizados e listas de verificações (checklists) que antecipem e abranjam falhas ou condições de emergência. Decisões equivocadas podem surgir a partir de interpretações incorretas e avaliações inapropriadas dos riscos envolvidos. As decisões podem ser influenciadas por informações imprecisas, ambiente estressor, estresse oriundo da esfera privada, ameaças latentes e pressões de ordem organizacional.

A Comunicação entre as equipes tem correlação direta com o incremento no automatismo das aeronaves. Esta tem uma função social quando ajuda na formação das relações em grupo, criando um ambiente que afeta o desempenho operativo das equipes (Anca et al., 2010:125). O processo comunicativo pode ser verbal ou não verbal e é baseado fundamentalmente em expectativas, ou seja, os interlocutores estruturam a informação transmitida e recebida de acordo com suas visões de mundo e o contexto sociocultural no qual estão inseridos. Desta forma, o transporte aéreo, marcado pelo viés globalizante, sempre procurou padronizar procedimentos e dizeres, evitando formas de comunicação que possam degradar o nível de segurança operacional. Outro aspecto se refere a doutrina de cotejar ou explicitar o entendimento da mensagem, permitindo que confusões sejam prontamente corrigidas. Briefings e Debriefings representam a efetiva comunicação verbal entre os membros de uma tripulação. Os briefings são necessários para ressaltar as tarefas e responsabilidades de cada membro da equipe, bem como apontar as características operacionais do voo. Os debriefings enfatizam o trabalho em equipe por meio do repasse das atividades executadas, salientando aspectos que devem ser aprimorados. $\mathrm{O}$ aspecto mais importante de um debriefing é o quê, e não quem está errado, e como prevenir as falhas ocorridas. Operacionalmente, se faz necessário que os tripulantes verbalizem, verifiquem e monitorem todas as instruções e ações que interfiram na condição do automatismo. A comunicação deficiente entre pilotos e controladores com o consequente risco potencial a segurança operacional é o item mais citado pela NASA no seu Sistema de Reportes para Segurança da Aviação.

\section{Segurança Operacional na Aviaçẵo}

Segurança é a ausência de riscos inaceitáveis (ICAO, 2009). Entende-se por Segurança Operacional o estado no qual o risco de lesões às pessoas ou danos aos bens é reduzido ou mantido em um nível aceitável, ou abaixo do mesmo, por meio de um processo contínuo de identificação de perigos e gerenciamento dos riscos. Portanto, a expressão se refere ao foco institucional na segurança das operações em aeronaves, conhecido anteriormente por segurança de voo (ANAC 2011).

A Organização de Aviação Civil Internacional (ICAO), bem como as agências reguladoras, em especial dos países filiados a ONU, tem cada vez mais focado sua atenção em prol da segurança operacional, de forma que o transporte aéreo apresente índices decrescentes de incidentes e acidentes.

Esta cultura baseada em segurança das operações de voo tem permeado cada vez mais as empresas aéreas por meio de procedimentos impostos pelas agências. Estes mecanismos evidenciam os fatores humanos em aviação, bem como adotam os cursos de CRM na rotina de qualificação e treinamento das equipes. Acidentes e incidentes são produto de ameaças e erros indevidamente gerenciados pelas equipes operacionais. A partir da premissa que ameaças e erros são inerentes ao cenário operativo e a condição humana, existe o desafio em evitar o avanço destes condicionantes por meio de contramedidas apropriadas. Este desafio é mais bem equacionado quanto maior for o domínio das equipes em relação aos regulamentos, procedimentos e programas.

É importante salientar que o simples cumprimento das diretrizes emanadas pelas agências reguladoras pode não garantir um arranjo institucional focado na segurança operacional e na importância dos fatores humanos em aviação. $O$ fato de cumprir um currículo imposto pela regulação pode não significar a efetiva aderência aos procedimentos propostos. A cultura organizacional necessita valorizar e fazer cumprir estes preceitos, adequando equipes e influenciando positivamente o grau de segurança operacional de uma empresa aérea. Neste cenário, faz-se importante o verdadeiro comprometimento dos gestores e dirigentes destas organizações, patrocinando verdadeiramente estas políticas, enfatizando a correlação entre segurança operacional e fatores humanos na mitigação de sinistros em aviação.

\section{Considerações finais}

A aplicação dos princípios do CRM permite a detecção incipiente de ameaças e administração efetiva dos erros. A ideia central de todos os cursos de CRM é a de adotar as melhores práticas no gerenciamento de ameaças e erros, reduzindo ou eliminado os elementos 
potencialmente perigosos que possam ser os percussores de um incidente ou acidente.

Pilotos devem estar qualificados e recorrentemente treinados a perceber que o voo seguro não engloba a total ausência de erros, e sim como estes problemas são administrados e conduzidos pela tripulação. Os elementos que conduzem ao acidente são o gerenciamento deficiente de uma situação errática até a consumação da consequência resultante, e não o erro do piloto em si. Desta forma, qualificação e treinamentos em simuladores e checks devem ser conduzidos no contexto de uma tripulação efetuando ações coordenadas e não avaliações de caráter individual.

O erro humano deve ser apreendido como um sintoma e não como a causa de algum problema. As pessoas estão sujeitas a limitações independentemente do grau de qualificação, treinamento e experiência prévia. Por meio de treinamentos recorrentes é possível mitigar a ocorrência de erros, praticando os procedimentos corretos, bem como as contramedidas. No entanto, a emergência de cenários secundados pelo erro é potencialmente infinita, impedindo o treinamento perfeito. $\mathrm{O}$ desafio passa pela utilização de um sistema de gerenciamento de erros, na qual as tripulações reconheçam as ameaças e corrijam erros, que inevitavelmente irão ocorrer, antes do aparecimento das consequências negativas. $O$ processo de instrução e avaliação deve abandonar o viés da culpabilidade no treinamento, proporcionando que as tripulações desenvolvam habilidades de reconhecer ameaças, detectando e administrando erros. Em termos práticos, se uma falha é rapidamente detectada pelos tripulantes, o erro em si, não ocorreu. Portanto, monitoramento efetivo se traduz em importante elemento na avaliação de erros.

Numa visão sistêmica, a função do co-piloto existe como elemento de suporte, reduzindo a carga de trabalho do comandante, mitigando a possibilidade de falha humana, desconstruindo a visão tradicional de ator redundante a ser utilizado como reserva eventual. Pela doutrina CRM o co-piloto é um participante ativo na construção de uma cultura operacional baseada na atuação em conjunto.

A eficiente e segura operação de uma aeronave passa por um processo integrativo, não segmentado de ações e comportamentos baseados em comunicação efetiva; consciência situacional em estado de alerta; capacidade coletiva na resolução de demandas, tomada de decisões e julgamento; liderança e anuência ratificadas pela tripulação; gerenciamento do stress e fadiga, bem como do relacionamento interpessoal proativo.
O produto de uma ação coletiva é dado pelas características individuais dos seus membros, pelo arranjo institucional da organização e pela qualidade da liderança existente. $O$ desempenho eficiente de uma equipe, inserido num ambiente de atividades complexas, requer que seus membros atuem de forma organizada, cumprindo tarefas no tempo disponível, realizando ações e interações conhecidas e compreendidas por todos.

$\mathrm{O}$ arranjo institucional ou cultura de segurança operacional de uma organização deve ser estruturado e difundido pela esfera diretiva, checadores e instrutores. Desta forma, o grau de aderência adotado pelas tripulações tende a ser consistente. As organizações devem monitorar os procedimentos praticados pelos tripulantes e demais funcionários, fazendo cumprir o arranjo institucional proposto. Processos induzidos e balizados pelas organizações apresentam maior efetividade quando comparados com aqueles essencialmente capitaneados por seus atores. Neste cenário, os cursos de CRM e programas como o LOFT passam a ter maior efetividade ao invés de simplesmente atenderem as exigências da agência reguladora.

Finalmente, ressalta-se a importância da cultura organizacional na estruturação das em fatores humanos, objetivando a redução de incidentes e acidentes na aviação, influenciando positivamente o grau de segurança operacional das organizações.

\section{Referências}

ANAC 2011. [Acesso em: 24 nov. 2014]. Disponível em: http:// www.pilotopolicial.com.br/sgso-sistemas-de-gerenciamento-daseguranca-operacional/

Anca J, Helmreich R, Kanki B. Crew Resource Management. San Diego: Elsevier; 2010.

Arato L, Cohen J. Civil Society and Political Theory. Cambridge: MIT Press; 1999

Blain ANJ. Pilots and Management: Institucional Relations in the UK Airlines. London: George Allen and Unwin; 1970.

Bourdieu P. O poder simbólico. Rio de Janeiro: Bertrend; 1998.

CENIPA 2014. [Acesso em: 16 dez. 2014]. Disponível em: file://C:/Users/Owner/Downloads/nsca\%203-13\%20(1).pdf

Cox G, McCubbins M. Legislative Leviathan: Party Government in the House. Berkley, Los Angeles, Oxford: University of California Press; 1993.

Downs A. Uma teoria econômica da democracia. São Paulo: EDUSP; 1999.

Goodin R. Institutions and Their Design. In: Goodin R. (Org.). The Theory of Institutional Design. Cambridge: Cambridge University Press; 1996.

Goodin R, Klingemann H. (Org.). A New Handbook of Political Science. Oxford: Oxford University Press; 1998.

Green R, Muir H, James M, Gradwell D, Green L. Human Factors for Pilots. Brookfield: Avebury Aviation; 1996. 
Hall P, Taylor R. Political Science and the Three New Institutionalisms. Cambridge: Harvard University; 1996. [Political Studies, XLIV].

ICAO 2009. Doc. 9859, 2.2.4. [Acesso em: 16 dez. 2014]. Disponível em: www.ulc.gov.pl/_download/.../safety_management manual_edycja_i.pdf

North D. Institutions, Institutional Change and Economic Performance. New York: Cambridge University Press; 1990.

Olson M. A lógica da ação coletiva. São Paulo: EDUSP; 1999.

Peters G. Institutional Theory in Political Science: The New Institutionalism. London and New York: Printer. 1999
Skocpol T. Protecting Soldiers and Mothers: The Political Origins of Social Policy. Cambridge: Cambridge University Press; 1992.

Tsebelis G. Jogos Ocultos: Escolha racional no campo da política comparada. São Paulo: EDUSP; 1998.

Weber M. Economia e Sociedade. Brasília: UNB; 1994.

Correspondence address:

Paulo Cezar Rodrigues Villas Boas

Rua Cel. Bordini, 882, apto. 602 - Moinhos de Vento

90.440-003 Porto Alegre, RS, Brasil

Tel.: (51) 8105-4701

<pvillas@gmail.com> 